\title{
The extent to which the passive voice is used in the scientific journal article, 1985-2015
}

\author{
David Banks ${ }^{1,2}$ (D)
}

Correspondence:

David.Banks@univ-brest.fr

'Université de Bretagne

Occidentale, Faculté des Lettres et

Sciences Humaines, 20 rue

Duquesne, 29238 Brest Cedex 3,

France

${ }^{2}$ Present Address: 2 rue des Saules,

29217 Plougonvelin, France

\begin{abstract}
Some recent research has suggested that use of the passive voice in scientific writing has declined over the last few years. This study attempts to see to what extent that is true. The corpus consists of 32 scientific articles with 8 taken from the publications of the Royal Society of London for each of the years 1985, 1995, 2005 and 2015. Half of the articles are from Series A (physical sciences) publications and half from Series B (biological sciences). Overall there is some evidence that passive use has declined for multi-authored papers, although this is clearer in Series A than in Series B. This is supported by an increase in the use of active verbs with first person pronoun subjects in Series A multi-authored papers. There is a tendency for active verbs with first person pronoun subjects to occur in mental process rather than material process. It is hypothesized that the more personal nature of mental process lends itself to active first person pronoun use, and that an increase in articles based on mathematical modeling, as opposed to experimental reports, has led to an increase in the proportion of mental process verbs, particularly those related to mathematical calculation.
\end{abstract}

\section{Introduction}

Ever since Barber's seminal (1962) article there has been a steady stream of research into the use of the passive voice in scientific writing. In that article Barber found that, in his sample of scientific texts, $28 \%$ of the non-modal verb forms were in the passive voice, the most common form being the simple present passive which accounted for $25 \%$. Since then the literature on the question of the use of the passive in scientific writing has assumed vast proportions. In this mass of literature some contributions have achieved classic status such as Tarone et al. 1981, and its follow-up, Tarone et al. 1998. Tarone et al. 1981 studies what might now be called a mini-corpus (Banks 2005a) of two astrophysics papers. The rate of passive use is shown to be lower than might have been expected. Active voice with a first person plural subject tends to be used when the authors wish to underline a personal contribution, while passive is used for established or standard procedures. Where a contrast is made, authors tend to use the active voice for their own work and the passive for the work of others. And authors use the passive for speculating on their own future work. Tarone et al. do however point out that these results may be specific to the subgenre of the astrophysics

(c) The Author(s). 2017 Open Access This article is distributed under the terms of the Creative Commons Attribution 4.0 International License (http://creativecommons.org/licenses/by/4.0/), which permits unrestricted use, distribution, and reproduction in any medium, provided you give appropriate credit to the original author(s) and the source, provide a link to the Creative Commons license, and indicate if changes were made. 
research article. When they returned to this question in 1998, Tarone et al. suggested that a pertinent difference between papers in astrophysics as opposed to many other (but not all) scientific fields, was that their rhetorical structure was that of logical argument rather than experimental report. Nevertheless, use of the passive has continued to be considered a significant resource in the writing of the scientific article. My own study of a corpus of papers in the field of oceanography (Banks 1994), showed that passives accounted for just over $30 \%$ of the finite verbs, which corresponded fairly well to the sorts of frequencies that had been found in a number of previous studies.

The justification of the use of the passive has most frequently been laid at the door of the idea that scientific writing should be impersonal. Cooray's claim that the passive "helps the writer to maintain an air of scientific impersonality" (Cooray 1967, 207) is fairly typical. However, more recently, some have claimed (Halliday 1988, Banks 2008a, 2008b) that passive use in scientific writing is a question of thematic structure. The writer, wishing to highlight his object of study, or his experiment, rather than himself, as the starting point of his clause, places it in thematic position, that is, at the beginning of the clause. One of the most common ways (but not the only way) of doing this is by using the passive.

It is curious that although the passive has been a standard resource for scientific writers over many decades, style manuals and instructions to authors have frequently argued in favour of avoiding the passive. Bennett studied a range of academic style manuals, and found that there were "a great many authors that argue categorically in favour of the active voice" $(2009,49)$. Minton $(2015)$, however, argues that while much of the opposition to the use of the passive is, in fact, opposition to inappropriate use of the passive, when appropriately used it has a perfectly justifiable place.

The passive voice is an intrinsic part of the English language and used appropriately to maintain the natural flow of writing and presentation of information, it is an essential feature of good writing. Its function is not to conceal or obfuscate, but to maintain stylistic patterns in the presentation of information that have established themselves for very valid reasons in the English language over centuries of usage (Minton 2015, 9).

Moreover, some, whom one might have thought ought to know better, feel free to pontificate on scientific style. For example, in 2002, Sir Robert May, the then President of the Royal Society, in a letter to a publication intended for science teachers, fulminated against the use of the passive in scientific writing. He wrote:

At the risk of going over-the-top, I would put my own view so strongly as to say that, these days, use of the passive voice in a research paper is more often than not, the hallmark of second rate work (May 2002, 2).

This was over the top indeed, since even a cursory glance at the papers published in the Royal Society's own journals shows that if he were correct much of what the Royal Society was publishing would have to be classed as "second rate"! Evidently competence in other fields does not necessarily give one competence in linguistic matters. 
This having been said, some linguistic researchers, notably Seoane and her collaborators (Seoane \& Loureiro-Porto 2005, Seoane 2006, Seoane \& Williams 2006), claim to have detected a relatively recent change, leading to a decrease in passive use in scientific writing. In Seoane and Loureiro-Porto 2005, the authors claim that "recent studies have shown that there is a dramatic decrease in the number of passives found in scientific British and American English in the $20^{\text {th }}$ century" $(2005,107)$. They found that while the rate of passives (i.e. number of passives as a percentage of passivizable finite verbs) was relatively stable from the beginning of the twentieth century until the 1960s, there was thereafter a considerable decrease, which was "more dramatic in American English" (2005, 109). Between the period 1960-75 and the period 1985-90, the rate of passive use fell from $66.4 \%$ to $58.7 \%$ of passivizable verbs for British English, and from $62.2 \%$ to $46.4 \%$ for American English. The authors consider the possibility that this change in passive use is part of a general trend towards colloquialization in scientific English. This, however, appears not to be the case since other markers of colloquialization have not changed in the same way, with the exception of first person pronouns, which can be directly related to the change in passive use. Seoane 2006 goes on to consider other possible explanations in addition to that of colloquialization. She considers and excludes the possibility that the change is due to a move towards a more subjective style, and the possibility that scientific discourse is becoming more personal and author-centred. She thinks that the drive to make scientific writing more effective is a more likely reason for the change. Similar points are put forward in Seoane and Williams 2006, where scientific discourse is contrasted with prescriptive legal discourse. Hyland and Jiang (2017) approach the question from the other end of the telescope, as it were, by considering whether academic writing is becoming more informal. They find that use of first person pronouns has increased in academic writing in general and in scientific writing in particular, most notably in biology where the use of first person pronouns has risen from 10.9 per 10,000 words in 1965 to 34.1 per 10,000 words in 2015. This may well be related to changes in passive use. Increasing use of first person pronouns was also noted by Lafuente Millán 2010, who found that it varied by discipline, and suggested that it involves an effort to balance authorial claims and appropriate modesty. Harwood 2005 underlines the self-promotional function of the use of first person pronouns.

Since the passive has frequently been considered the hallmark of scientific writing, the changes reported in these studies, to the extent that they are true, are indeed significant. My own work (Banks 2008a), on an admittedly small sample, indicated that at least until 1980 the rate of passives was maintained at over 30\% of finite verbs, and that the use of first person pronouns had dwindled to almost nothing. It is therefore of interest to see to what extent these claims that use of the passive is decreasing are true. This paper is an attempt to provide a contribution to the discussion on this important question.

\section{Corpus}

The corpus I will use for this study is derived from the publications of the Royal Society. The corpus contains samples for the years 1985, 1995, 2005 and 2015. For the years 1985 and 1995, the texts used are taken from the Philosophical Transactions. In 1997 a decision was taken to move articles of primary research from the Philosophical 
Transactions to the Proceedings of the Royal Society; from then on the Philosophical Transactions would publish theme-based series of review articles and monographs on individual topics (Atkinson 1999, Banks 2008a). Consequently the texts for 2005 and 2015 are taken from the Proceedings. However, the date of 1997 does not appear to have been a neat cut-off point and some of the articles that turn up in the pre-1997 part of the sample do have a state-of-the-art flavour. Nevertheless, I felt it invidious to alter the corpus post-factum and these articles have been retained in the corpus. The Philosophical Transactions and the Proceedings both produce an A Series and a B Series, the A Series dealing with mathematical, physical and engineering sciences, and the B Series with biological sciences. Four articles from the A Series, and four from the B Series were selected for each of the dates. The choice was made by chance, if not technically random, ease of access being a pragmatic criterion. The details of the corpus are given in Appendix 1.

No attempt has been made to distinguish between American and British varieties. In fact, with this corpus such an attempt would be fairly difficult. For the 32 articles in the corpus, there is a total of 105 authors or co-authors, five of whom give two institutional addresses, including one article which lists 31 co-authors, three of whom give two institutional addresses, in 10 different countries. While an institutional address in an English-speaking country is no guarantee that the author is a native-speaking anglophone, it can be noted that of the 110 institutional addresses given, 70 are in English-speaking countries, and 40 in non-English-speaking countries. Details are given in Appendix 2.

\section{Overall results}

The finite verbs have been classified into those that are active, but where a passive equivalent exists (Act), those that are passive (Pass), and those that are active in form, but where no passive equivalent exists (NP).

(1) The description of the development and structure of detonation waves provides a comprehensive illustration of all the dynamic effects of combustion presented here. (Oppenheim 1985) ${ }^{1}$

(2) The spectra presented in Fig. 5 are believed to originate from single crystallites. (Brus \& Trautman 1995)

(3) Secondly, the types of morphological characters used (metric/continuous or non-metric/meristic) vary widely among studies. (Hartl et al. 1995)

Example (1) shows an active form which has a potential passive equivalent (cf. A comprehensive illustration ... was provided by the description ...); (2) is an example of a passive form; (3) is an example of the NP category, active in form with no passive equivalent (the clause has no component which could function as the potential subject in a putative passive form). The NP category is made up basically of intransitive verbs, including a large number of copulas. The decision as to whether a clause has an active/ passive equivalent might be thought to be to some extent subjective, but is, I think non-controversial. In Banks 2008a, I showed that articles in the physical sector, have developed at a different rate to those in the biological sector. For example, experimental articles occurred in the physical sector from the very beginning in 1665, whereas 
Table 1 Overall results

\begin{tabular}{lllll}
\hline A Overall & & & & \\
& 1985 & 1995 & 2005 & 2015 \\
& $n=3738$ & $n=1107$ & $n=1132$ & $n=1775$ \\
Act & $24 \%$ & $21 \%$ & $36 \%$ & $28 \%$ \\
Pass & $30 \%$ & $30 \%$ & $16 \%$ & $31 \%$ \\
NP & $46 \%$ & $50 \%$ & $47 \%$ & $41 \%$ \\
B Overall & & & & \\
& 1985 & $n=1569$ & 2005 & 2015 \\
& $n=1569$ & $30 \%$ & $n=508$ & $n=911$ \\
Act & $24 \%$ & $29 \%$ & $35 \%$ & $28 \%$ \\
Pass & $24 \%$ & $42 \%$ & $39 \%$ & $41 \%$ \\
NP & $52 \%$ & & & $41 \%$ \\
\hline
\end{tabular}

articles in the biological sector were initially observational, and experimental articles did not begin appearing until the mid-nineteenth century. In the late nineteenth century, the physical sector began to produce articles based on mathematical modelling rather than experiment, but this had not, at least up to 1980, begun to affect the biological sector. Consequently results for the physical sector, Series A articles, and the biological sector, Series B articles, will be given separately in this study. Nevertheless, it is probable that other feature distribution differences will be found in finer subgenre categories, and as Biber and Gray (2013) have warned, we should not underestimate the effects of subgenre differences. Table 1 gives the overall results for the two series at the four time points. ${ }^{2}$

Initially, the picture presented does not seem particularly clear. In the case of Series A, the percentages of active verbs are higher in the second half of the period, but the percentage falls between 2005 and 2015. In the case of Series B the percentage rises until 2005 but then falls back to a figure lower than that of 1995. It might be thought that the presence of the NP category (non-passivizable verbs) is obscuring the results, but this does not appear to be the case. Table 2 shows the results when the percentages are given of passivizable verbs only.

However, a factor that is a more likely candidate for obscuring the results is the fact that the sample includes a number of articles by single authors. In the A Series, this is the case of one article in 1985, two in 1995, two in 2005, and one in 2015; in Series B, it is the case of 2 articles in 1985 and one in 1995 . When the single-authored papers are removed, the results shown in Table 3 emerge.

Table 2 overall results for passivizable verbs

\begin{tabular}{ccccc}
\hline & 1985 & 1995 & 2005 & 2015 \\
\hline Series A & & & & \\
Act & $44 \%$ & $41 \%$ & $69 \%$ & $54 \%$ \\
Pass & $56 \%$ & $59 \%$ & $31 \%$ & $46 \%$ \\
Series B & & & & \\
Act & $50 \%$ & $51 \%$ & $57 \%$ & $48 \%$ \\
Pass & $50 \%$ & $49 \%$ & $43 \%$ & $52 \%$ \\
\hline
\end{tabular}


Table 3 Results for multi-author papers

\begin{tabular}{lllll}
\hline Series A & & & & \\
& 1985 & 1995 & 2005 & 2015 \\
& $n=3286$ & $n=319$ & $n=719$ & $n=1143$ \\
Act & $24 \%$ & $19 \%$ & $31 \%$ & $44 \%$ \\
Pass & $30 \%$ & $28 \%$ & $26 \%$ & $25 \%$ \\
NP & $46 \%$ & $52 \%$ & $52 \%$ & $31 \%$ \\
Series B & & & & \\
& 1985 & 1995 & 2005 & 2015 \\
& $n=635$ & $3=1330$ & $n=508$ & $n=911$ \\
Act & $19 \%$ & $29 \%$ & $35 \%$ & $28 \%$ \\
Pass & $29 \%$ & $41 \%$ & $26 \%$ & $31 \%$ \\
NP & $52 \%$ & & $39 \%$ & $41 \%$ \\
\hline
\end{tabular}

Here it might be possible to see evidence for increasing use of the active voice in the Series A subsample. The rate for 1995 is lower than that for 1985, but thereafter the rate increases from 19\% in 1995 to $44 \%$ in 2015. The situation for the Series B articles is less clear. Although the rate rises from 19\% in 1985 to $35 \%$ in 2005, it then falls back to $28 \%$ in 2015 , lower than the 1995 rate.

It is also possible to look at the figures for the single-authored articles, but it should be noted that there are never more than two for any given series and year, and in three cases (A Series 1985 and 2015, and B Series 1995) there is only one. In B Series 2005 and 2015 there are no single authored papers. The results are shown in Table 4.

For Series A, the rate of active use is similar for the years 1985, 1995 and 2015, but the year 2005 stands out as being significantly different. The passive and nonpassivizable verb rates are similar for the years 1985 and 1995. By 2015 the rate of passives seems to have increased at the expense of non-passivizable verbs, with 2005 again being rather different. However, since the number of papers is here very small, one cannot exclude the possibilty that this is due to the individual styles of the authors concerned. For Series B, single authored articles only occur in the years 1985 and 1995,

Table 4 Results for single-author papers

\begin{tabular}{lllll}
\hline Series A & & & & \\
& 1985 & 1995 & 2005 & 2015 \\
& $n=467$ & $n=807$ & $n=413$ & $n=532$ \\
Act & $23 \%$ & $21 \%$ & $43 \%$ & $20 \%$ \\
Pass & $34 \%$ & $32 \%$ & $15 \%$ & $46 \%$ \\
NP & $43 \%$ & $47 \%$ & $42 \%$ & $34 \%$ \\
Series B & & & & 2015 \\
& 1985 & 1995 & - & - \\
& $n=934$ & $n=239$ & - & - \\
Act & $28 \%$ & $29 \%$ & - & - \\
Pass & $21 \%$ & $25 \%$ & - & - \\
NP & $51 \%$ & $46 \%$ & & \\
\hline
\end{tabular}


but the figures for these two years are similar. It might also be noted that the figures for single authored papers are similar to those for multi-author papers for the years 1985 and 1995, but, at least for Series A, they are considerably different for the years 2005 and 2015.

\section{Use and non-use of first person pronoun subjects}

It has frequently been claimed that the use of the passive in scientific discourse is a way of not mentioning the identity of the agent, and thus making the discourse more impersonal. According to Seoane "a basic function of the passive in scientific discourse ... is to defocus or suppress the agent in order to make the discourse impersonal" (2006, 201). Hence, an increase in the use of actives at the expense of passives can be seen to "imply that authors are now not relegated but made central to scientific discourse" (2006, 201). This means that if there has been a switch from passive verbs whose supposed agent is the author, to an active form, then one can presume that the active form will most usually occur with a first person pronoun subject. In Table 5, active verbs with a first person pronoun subject (weA) (the count includes a small number of verbs with no passive equivalent and a small number of passives with a first person pronoun subject, but the numbers are so small that they do not alter the overall picture) are given as a percentage of passivizable verbs, and these are compared with the percentage of passive verbs whose supposed agent is the author or a group which includes the author (Pwe). Example (4) illustrates the weA category.

(4) Within the O. mucofloris sample $(n=18)$ we detected seven unique haplotypes of 507 bp observing no indels or stop codons (Glover et al. 2005, 2590).

The Pwe category is fairly wide, ranging from examples where the supposed agent is clearly the author(s), such as (5), to those which are general but where the author(s) are presumed to be included, such as (6).

(5) The rest of the paper is organized as follows. (Cicconofri \& DeSimone 2015)

Table 5 weA and Pwe as percentage of passivizable verbs

\begin{tabular}{lllll}
\hline Series A & & & & \\
& 1985 & 1995 & 2005 & 2015 \\
& $n=1769$ & $n=152$ & $n=347$ & $n=788$ \\
weA & $18 \%$ & $14 \%$ & $21 \%$ & $30 \%$ \\
Pwe & $23 \%$ & $36 \%$ & $27 \%$ & $28 \%$ \\
Series B & & & & 2015 \\
& 1985 & 1995 & 2005 & $n=539$ \\
& $n=305$ & $n=786$ & $n=310$ & $18 \%$ \\
weA & $9 \%$ & $16 \%$ & $21 \%$ & $37 \%$ \\
Pwe & $44 \%$ & $38 \%$ & $31 \%$ & \\
\hline
\end{tabular}


(6) Computational models of the heart are increasingly used to improve our understanding of cardiac physiology, including the effect of specific genetic changes and animal models of disease (Land et al. 2015).

In (5), obviously only the authors can organize their paper; in (6) it seems reasonable to suppose that the authors are included among those who increasingly use computational models of the heart.

Since it seems likely that this feature will be different in single authored papers as opposed to multi-author papers, and there is some evidence that single authors tend to avoid using first person pronouns (Lafuente Millán 2010), the results given here are those for multi-author papers only.

For Series A, it is possible to detect an increase in the use of active verbs with first person pronoun subjects, at least from 1995 onwards, rising from 14\% of passivizable verbs in that year to $30 \%$ in 2015 . The year 2015 is the only one in this sample where the weA type is more frequent than the Pwe type. Hence the evidence that we saw above for an increase in the use of active voice seems to be corroborated here by the increase in the use of first person pronoun subjects with those active verbs.

However, the same cannot be said of Series B. There is an increase between 1985 and 1995, but thereafter the rate remains relatively stable. Moreover, it will be noted that the frequency of the Pwe type is consistently higher than weA. Even in Series A, if passive verbs with a presumed author agent are considered as potential candidates for becoming active verbs with a first person pronoun subject, then even in 2015, only just over half of the potential has been taken up.

On the other hand, averages can sometimes be misleading. Saying that 30\% of passivizable verbs are active with a first person pronoun subject in the Series A 2015 papers may give the impression that this is representative of the individual papers in that group. In fact, the average figure masks wide differences in individual papers. Of the three multi-author papers concerned here, the figures for individual articles are $17 \%, 18 \%$ and $61 \%$. Hence, the average is greatly affected by a single high figure. It might be thought that this is placing too much weight on a single figure, but one might also hypothesize that this indicates that, for gatekeepers, the use or non-use of first person pronouns is not (or is no longer) a stylistic criterion. So, in other terms, whether authors thematize the scientific matter or the scientist no longer seems pertinent to those vetting the articles. For the 2015 Series B papers the range for individual papers is 9 to 26\%. Ten years earlier, in 2005, our small sample turned up, for Series A, one article which had no examples of weA at all, the others having $31 \%$ and $32 \%$. The range for the 2005 Series B articles was 8 to $33 \%$.

As suggested above, single authors might be expected to write differently in this respect. This indeed appears to be the case, since for the Series A articles the percentage of passivizable verbs which are active with a first person pronoun subject, are never more than $2 \%$, with one author not using this resource at all, and one significant exception. In the two articles by single authors which turn up in the 2005 sample $36 \%$ of the passivizable verbs are active with first person pronoun subjects (31\% in one of the articles, $37 \%$ in the other). One factor which may be relevant is that, unlike most of the articles in the corpus, these two papers are mathematical in nature, so it is not impossible that subgenre differences have a part to play here (Biber \& Gray 2013), and 
may provide a possible explanation for the high rate of weA examples found in these two papers. Nevertheless, even allowing for exceptions, it does seem true to say that there is still high resistance to the use of first person pronouns in singleauthored papers.

\section{Process type}

It is possible that the relative use of passives and actives with first person pronoun subjects varies depending on the type of process involved. I have therefore analysed weA and Pwe examples according to the process type of the verb concerned. The process types I use are based on those defined in Systemic Functional Linguistics (Halliday 2014), which provides a framework which is particularly suitable for this type of analysis. I use a system of five process types (Banks 2005b, 2016): material processes are actions or events of a physical nature; mental processes are events of a cerebral nature; these are frequently subdivided into cognitive (such as 'think'), affective (such as 'like'), and perception (such as 'see'); the majority of mental processes in academic articles are of the cognitive type (in the case of the scientific journal article, this will include, significantly, processes relating to mathematical calculation and computer analysis); relational processes link an entity to one of its characteristics, or to another entity; verbal processes are processes of communication; and existential processes state the existence of an entity. It is difficult to envisage a passive form for this final category and it will not concern us further here. O'Donnell et al. 2008 showed that there is a range of interpretations of process types, even among those using the Systemic Functional framework, from a more grammatical viewpoint to a more conceptual one. My own analysis is towards the conceptual pole of this cline. The following is an example of material process.

(7) Here, the hyomandibula is supported on a lateral buttress over the jugular vein ... (Brazeau \& de Winter 2015).

The following is an example of mental process.

(8) We can anticipate that FCS will re-emerge as a useful tool, especially in the area of coupled reaction and diffusion in the next few years (Birmingham et al. 1995).

The following is an example of a process which to relates to mathematical calculation and is also encoded as mental process.

(9) Equation (2.6) is integrated using the linearly implicit spectral method of Fornberg \& Driscoll (1999) which treats carefully the inherent stiffness due to high wavenumbers in the equation for the Fourier components (Johnson \& Vilenski 2005).

The following is an example of relational process.

(10) Gene regulatory networks and modules are central for the control and timing of organismal development (Bråte et al. 2015). 
And the following is an example of verbal process.

(11)It has been suggested that these differences will have a marked effect on biofilm permeability and any permeability-selective behaviour is likely to effect ecology ... (Birmingham et al. 1995).

The percentage distribution of examples of the weA type according to the process concerned is given in Table 6 .

It is clear that of those active verbs with a first person pronoun that occur in Series A articles the vast majority are examples of mental process. Between $60 \%$ and $75 \%$ of the weA types are examples of mental processes depending on the year. It will be remembered that in this study this includes both prototypical mental processes such as "consider", "estimate", "believe" and "infer", as well as those which are more typically processes of mathematical calculation or computer analysis, such as "calculate", "analyse", "linearize" and "derive". There is no evidence of any real change over time, as the figure for 1985 is the same as that for 2015. On the other hand, weA types are very rarely material process, with the exception of 1995, where the raw figures are low in any case. The second most common type of process in the weA sample is verbal, and examples of this process type vary from 14 to $22 \%$ depending on the year. Relational processes are also extremely rare. These are mainly cases of "need" and "require", and the small number of non-passivizable cases have been included here, and these are mainly "have" and "be".

In Series B, the general trend is similar. Mental process is by far the largest category, though to a lesser extent than in Series A, ranging in this case from 54 to $66 \%$. Material processes account for a slightly higher percentage than in Series A, though remaining relatively small, with the exception of 2005. Verbal process is again the second largest group, but providing greater variability from year to year, ranging from 6 to $29 \%$.

Table 6 weA by process type

\begin{tabular}{lllll}
\hline Series A & 1985 & 1995 & 2005 & 2015 \\
& $n=352$ & $n=21$ & $n=72$ & $n=240$ \\
Material & $2 \%$ & $24 \%$ & $1 \%$ & $4 \%$ \\
Mental & $75 \%$ & $62 \%$ & $60 \%$ & $75 \%$ \\
Relational & $4 \%$ & - & $2 \%$ & $6 \%$ \\
Verbal & $19 \%$ & $14 \%$ & $22 \%$ & $15 \%$ \\
Series B & & & & \\
& 1985 & 1995 & 2005 & $n=80$ \\
& $n=24$ & $n=130$ & $3=63$ & $18 \%$ \\
Material & $13 \%$ & $5 \%$ & $57 \%$ & $54 \%$ \\
Mental & $58 \%$ & $66 \%$ & - & $4 \%$ \\
Relational & - & $12 \%$ & $6 \%$ & $25 \%$ \\
Verbal & $29 \%$ & & & \\
\hline
\end{tabular}


Table 7 Chances of weA occurring

\begin{tabular}{ccccc}
\hline & 1985 & 1995 & 2005 & 2015 \\
\hline Series A & & & & \\
Material & $1: 56.3$ & $1: 8.0$ & $1: 12.0$ & $1: 3.6$ \\
Mental & $1: 2.2$ & $1: 2.9$ & $1: 2.6$ & $1: 1.8$ \\
Verbal & $1: 2.7$ & $1: 2.6$ & $1: 2.5$ & $1: 2.2$ \\
\hline
\end{tabular}

Another way of looking at this question is to consider, for each process type, where the presumed agent of the process is the author (or authors), or a group which includes him, what the chances are of it being encoded as an active with a first person pronoun subject. This can be calculated by taking the total number of weA and Pwe forms and dividing the total by the number of weA forms. In Table 7 , this is done for material mental and verbal processes in the multi-author papers in the Series A sample.

Thus, in 1985, there were 7 weA types and 387 Pwe types that were material process in the Series A sample. So, the chances of a weA type occurring is $(7+387) / 7$. The result (rounded to the first decimal place) is 56.3. We can therefore say that in 1985 a mental process with the author as supposed agent in a Series A article would have a 1: 56.3 chance of being encoded in the weA form (i.e. for every 56.3 occurrences there is likely to be one weA form). For example, the authors of one article say the following.

(12) In $\$ 3$ we describe and discuss our observations, first for free convection, then for mixed convection. (Chen et al. 1985)

The chances of the authors making the decision to encode this in weA form rather than its Pwe alternative (as in (13) are one in 56.3.

(13) In $\$ 3$ our observations are described and discussed first for free convection, then for mixed convection.

So, it can be seen that in 1985 the chances of a material process being in the weA form are very low, whereas the chances of mental and verbal processes being in the weA form are relatively high. The chances of a material process being in the weA form are greatly increased from 1995 onwards, being 1: 8.0 for that year, and rising to 1: 3.6 in 2015. On the other hand, the chances of mental and verbal processes being in the weA form change little over the period studied. Part of the explanation of this situation probably lies in the fact that overall there is a massive reduction in the use of material processes after 1995.

If one looks at multi-authored papers only, then in 1985, in the Series A articles, a weA or Pwe material process occurs on average once every 8.3 finite clauses, and once every 8.0 clauses in 1995 . In 2005, however, the figure is once every 55.3 clauses, and once every 31.8 clauses in 2015. I would hypothesize that increasing use of mathematical modelling in the scientific article has led to a drastic reduction in the number of material processes being used. This then gives the impression of a shift to the use of mental processes. Scientific authors are more ready to use a first person pronoun subject with a mental or verbal process than with a material process, passive forms being preferred with material processes, but as overall numbers of material processes 
Table 8 Chances of weA occurring

\begin{tabular}{ccccc}
\hline & 1985 & 1995 & 2005 & 2015 \\
\hline Series B & $1: 26.0$ & $1: 25.7$ & $1: 3.5$ & $1: 4.7$ \\
Material & $1: 4.2$ & $1: 2.5$ & $1: 2.1$ & $1: 4.1$ \\
Mental & $1: 2.6$ & $1: 2.3$ & - & $1: 1.5$ \\
Verbal & & & & \\
\hline
\end{tabular}

dwindle, the percentage of passive forms fall giving a corresponding rise in the percentages of mental and verbal processes.

The situation for Series B papers seems fairly similar. The results for Series B are given in Table 8.

Here, the only notable difference with the Series A papers is that rise in the chances of a weA material process occurring comes a little later in time. The chances are fairly low in 1985 and 1995, but much greater in 2005 and 2015. For mental and verbal processes there is little change over time, with slightly more variation than in the Series A articles.

In single-author papers, weA forms are used sparingly, with some striking individual exceptions. The details are given in Table 9, but it must again be remembered that there are never more than two papers for any year, and sometimes only one. These figures are then given to complete the factual details about this small corpus, but it must be remembered that they are precisely that: facts about this corpus; and it would not be appropriate to attempt any extrapolation on the basis of these figures. At best they might provide working hypotheses to be tested by future research.

Since the figures here are so small, they have been given here as raw numbers rather than as percentages. To the extent that anything can be said on such a small sample, it can be noted that most single authors use very few weA forms. For the Series A papers, a total of six articles are concerned. Of these one in 1995 and one in 2015 use no weA forms at all. Of the others, three papers use them fairly modestly; one paper in each of the years 1985, 1995 and 2005 use five, four and 12 examples respectively. However, the one remaining paper from 2005 uses them relatively frequently, having 73 examples. In the Series B papers, only three articles are concerned, with five and 16 examples in 1985, and one in 1995. Hence it would seem that most single authors of papers are very reticent about using first person pronoun subjects, but that

Table 9 Numbers of weA forms in single-author papers

\begin{tabular}{|c|c|c|c|c|}
\hline & 1985 & 1995 & 2005 & 2015 \\
\hline \multicolumn{5}{|l|}{ Series A } \\
\hline Material & 1 & - & - & - \\
\hline Mental & 4 & 1 & 60 & - \\
\hline Relational & - & 3 & 9 & - \\
\hline Verbal & - & - & 16 & - \\
\hline \multicolumn{5}{|l|}{ Series B } \\
\hline Material & - & - & - & - \\
\hline Mental & 16 & - & - & - \\
\hline Relational & 3 & - & - & - \\
\hline Verbal & 2 & 1 & - & - \\
\hline
\end{tabular}


individual authors may take a different line and this is not seen as an impediment to publication by gatekeepers. The pronoun almost inevitably actually used is "we", frequently an inclusive "we". There are only five examples of the singular pronoun "I" in single-author papers in the whole corpus, and these occur in the two 1985 B Series articles.

\section{Final remarks}

On the basis of this small study, there does seem to be some evidence that the use of the active voice with first person pronoun subjects is increasing at the expense of passive forms. This change is however clearer in the Series A articles than in the Series B articles. In multi-authored papers, the use of weA forms is more common in mental processes than in material processes. Some commentators (e.g. Tarone et al. 1981) have suggested that use of the active form may be motivated by a desire to highlight a process as being a personal contribution. Intuitively mental processes might be seen as being more personal than material processes; only I can have my thoughts, but, in theory, anyone can repeat a physical action. I would hypothesize that as research articles become more a question of mathematical modelling and computer analysis, the overall numbers of material processes is diminishing, with a consequent rise in the proportion of mental processes, particularly those relating to calculation. Systemic Functional Linguistics provides an excellent tool for bringing out this aspect of scientific text. In particular, from the point of view of this study it provides a framework for the analysis of process types which has been adapted for the purposes of this paper. Since mental processes can be more easily encoded in the active form, because they are felt as somehow more personal, the percentage of active mental processes rises. Once again, however, this picture seems clearer in the case of Series A than that of Series B. This would seem to correspond to a general trend whereby changes in style occur first in the physical sciences, and are only adopted by the biological sciences at a later date (Banks 2008a). In single-author papers, weA forms are, in general, used very rarely. However, they may be used fairly extensively by individual authors, and this seems acceptable to gatekeepers.

Hence, I am suggesting that the perceived decrease in the use of passive forms, and consequent increase in the use of active forms with first person subjects, in Series A articles, is due to an increase in the use of mathematical modelling in the physical sector. The processes involved in mathematical modelling include significant numbers of mental processes which are more conducive to the use of active forms, than is the case with material processes. The use of mathematical modelling began to affect the Series B articles at a later date, and while there is evidence that Series B is following the same route as Series A, the situation is for the moment less clear.

This study has been carried out on a small sample. It is therefore presented with all the provisos that such a sample requires. Nevertheless the picture which seems to be emerging is compatible with the available evidence. It would nonetheless merit confirmation in a larger corpus. We have seen that there are differences between the Series A articles and the Series B articles. I would expect further differences to be revealed by studies on finer generic differences between disciplines and sub-disciplines, and on disciplines not represented here, such as medicine. It might also be useful in future studies 
to distinguish processes of mathematical calculation and computer analysis from other forms of mental process. ${ }^{3}$

\section{Endnotes}

${ }^{1}$ Relevant parts of examples are printed in bold.

${ }^{2}$ Throughout, percentages are given to the nearest integer. Any discrepancies are due to rounding.

${ }^{3}$ I would like to thank two anonymous Functional Linguistics reviewers for their insightful comments which have enabled me to improve on the initial version of this article. It goes without saying that I alone am responsible for any shortcomings that remain.

\section{Appendix 1: Corpus}

1985

Philosophical Transactions A 315

Oppenheim, A.K.: Dynamic features of combustion.

\section{Philosophical Transactions A 316}

Chen, K.S., J.A.C. Humphrey \& F.S. Sherman: Free and mixed convective flow of air in a heated cavity of variable rectangular cross section and orientation.

Mysak, L.A., G Salvadè, K. Hutter \& T. Scheiwiller: Topographical waves in a stratified elliptical basin, with application to the lake of Lugano.

Quinn, T.J. \& J.E. Martin: A ra\&diametric determination of the Stafan-Boltzmann constant and thermodynamic temperatures between $-40{ }^{\circ} \mathrm{C}$ and $+100{ }^{\circ} \mathrm{C}$.

\section{Philosophical Transactions B 312}

Jacobson, M. \& S.L. Klein: Analysis of clonal restriction of cell mingling in Xenopus.

Kenyon, Cynthia: Cell lineage and the control of Caenorhabditis elegans development.

Stent, G.S.: the role of cell lineage in development.

Weisblat, D.A. \& M. Hankland: Cell lineage and segmentation in the leech.

\section{5}

Philosophical Transactions A 353

Binh, Vu Thien, N. Garcia \& V. Semet: Nanotips and nonosources: applications to low-energy-electron microscopy.

Broers, Alec N.: Fabrication limits of electron beam lithography and of UV, X-ray and ion-beam lithographies.

Brus, L.E. \& J.K. Trautman: Nanocrystals and nano-optics.

Drexler, K.E.: Molecular manufacturing: perspectives on the ultimate limits of fabrication.

Philosophical Transactions B 350

Birmingham, J.J., N.P. Hughes \& R. Trelloar: Diffusion and binding measurements within oral biofilms using fluorescence photobleaching recovery methods. 
Davis, Brian K.: Significance of strand configuration in self-replicating RNA molecules.

Fredkin, D.R., J.A. Rice, D. Colquhoun \& A.J. Gibb: Persistence: a new statistic for characterizing ion-channel activity.

Hartl, Günther B., Franz Suchentrunk, Rudolf Willing \& Renate Petznek: Allozyme heterozygosity and fluctuating asymmetry in the brown hare (Lepus europaeus): a test of the developmental homeostasis hypothesis.

\section{5}

Proceedings A 461

Biktashev, Vadim N. \& Mikhail A. Tsyganov: Solitary waves in excitable systems with cross-diffusion.

Cañizo Rincón, José Alfredo: Asymptotic behavior of solutions to the generalized Beck-Döring equations for general initial data.

Jansons, Kalvis M.: Brownian excursion with a single mark.

Johnson, E.R. \& G.G. Vilenski: Two-dimensional leaps in near-critical flow over isolated orography.

\section{Proceedings B 272}

Astles, Philip A., Allen J. Moore \& Richard F. Preziosi: Genetic variation in response to an indirect ecological effect.

Glover, Adrian G., Björn Källström, Craig R. Smith \& Thomas G. Dahlgren: World-wide whale worms? A new species of Osedax from the shallow north Atlantic.

Kubodera, Tsunemi \& Kyoichi Mori: First-ever observations of a live giant squid in the wild.

Jutz, S.J., E.P. Hoberg, L. Polley \& E.J. Jenkins: Global warming is changing the dynamics of Arctic host-parasite systems.

\section{5}

Proceedings A 471

Ciccinofri, Giancarlo \& Antonio DeSimone: A study of snake-like locomotion throughthe analysis of a flexible robot model.

Huang, D., S. Chernyshenko, P. Goulart, D. Lasagna, O. Tutty \& F. Fuentes: Sum-ofsquares of polynomials approach to nonlinear stability of fluid flows: an examples of application.

Land, Sander, Vlatcheslav Gurev, Sander Arens, Christoph M. Augustin, Lukas Baron, Robert Blake, Chris Bradley, Sebastian Castro, Andrew Crozier, Marco Favino, Thomas E. Fastl, Thomas Fritz, Hao Gao, Alesia Gizzi, Boyce E. Griffith, Daniel E. Hurtado, Rolf Krause, Xiaoyu Luo, Martyn P. Nash, Simone Pezzuto, Gernot Plank, Simone Rossi, Daniel Ruprecht, Gunnar Seeman, Nicolas P. Smith, Joakim Sundnes, J. Jeremy Rice, Natalia Trayanova, Dafang Wang, Zhinuo Jenny Wang \& Steven A. Neiderer: Verification of cardiac mechanics software: benchmark problems and solutions for testing active and passive material behavior.

Mao, X.: Sensitivity of forces to wall transpiration in flow past an aerofoil. 


\section{Proceedings B 282}

Bråte, Jon, Marcin Adamski, Ralf S. Neumann, Kamran Shalchian-Tabrizi \& Maja Adamska: Regulatory RNA at the root of animals: dynamic expression of developmental lincRNAs in the calcisponge Sycon ciliatum.

Brazeau, Martin D. \& Valerie de Winter: The hyoid arch and braincase anatomy of Acanthodes support chondrichthyan affinity of 'acanthodians'.

Champredon, David \& Jonathan Dushoff: Intrinsic and realized generation intervals in infectious-disease transmission.

Puttick, Mark N., \& Gavin H. Thomas: Fossils and living taxa agree on patterns of body mass evolution: a case study with Afrotheria.

\section{Appendix 2 : No. of authors per country of institutional address}

Australia 2

Austria 6.

Belgium 1.

Canada 6.

Chile 2.

France 1.

Germany 4.

Italy 3.

Japan 2.

Netherlands 2.

New Zealand 5.

Norway 7.

Russia 1.

Spain 2.

Sweden 2.

Switzerland 7.

UK 32.

USA 25.

Received: 18 April 2017 Accepted: 17 August 2017

Published online: 07 September 2017

\section{References}

Atkinson, Dwight. 1999. Scientific Discourse in Sociohistorical Context. In The Philosophical Transactions of the Royal Society of London, 1675-1975. Mahwah. NJ: Lawrence Erlbaum Associates.

Banks, David. 1994. Writ in water, aspects of the scientific journal article. Brest: ERLA, Universite de Bretagne Occidentale. Banks, David. 2005a. The case of Perrin and Thomson: An example of the use of a mini-corpus. English for Specific Purposes 24 (2): 201-211.

Banks, David. 2005b. Introduction à la linguistique systémique fonctionnelle de l'anglais. Paris: L'Harmattan.

Banks, David. 2008a. The development of scientific writing. In Linguistic features and historical context. London, Equinox.

Banks, David. 2008b. The significance of thematic structure in the scientific journal article, 1700-1980. In Systemic

Functional Linguistics in Use, Odense Working Papers in Language and Communications 29, ed. Nina Nørgard. http:// www.sdu.dk/da/Om_SDU/Institutter_Isk/Forkningspublikationer/OWPLC.aspx.

Banks, David. 2016. On the (non)necessity of the hybrid category behavioural process. In Hybridity in Systemic Functional Linguisics. Grammar, text and discursive context, ed. Donna R. Miller and Paul Bayley, 21-40. Sheffield: Equinox.

Barber, C.L. 1962. Some measurable characteristics of modern scientific prose. In Contributions to English syntax and philology, ed. F. Behre, 21-43. Stockholm: Almqvist \& Wiksell.

Bennett, Karen. 2009. English academic style manuals: A survey. Journal of English for Academic Purposes 8: 43-54.

Biber, Douglas, and Bethany Gray. 2013. Being specific about historical change: The influence of sub-register. J Engl Linguist 41 (2): 104-134.

Cooray, Mahinda. 1967. The English passive voice. Engl Lang Teach 21 (3): 203-210. 
Halliday, M.A.K. 1988. On the language of physical science. In Ghadessy M., (ed.). Registers of Written English: Situational factors and linguistic features. London: Pinter, 162-178. [reprinted in Halliday \& Martin (1993: 54-68) and Halliday (ed. J. Webster)(2004): 140-158].

Halliday, MAK. (revised by Christian MIM. Matthiessen). 2014. Halliday's Introdution to functional grammar, $4^{\text {th }}$. edn. London: Routledge.

Harwood, Nigel. 2005. 'Nowhere has anyone attempted ... In this article I aim to do just that'. A corpus-based study of self-promotional / and we in academic writing across four disciplines. Journal of Pragmatics 37 (8): 1207-1231.

Hyland, Ken, and Feng (Kevin) Jiang. 2017. Is academic writing becoming more informal? English for Specific Purposes 45: 40-51.

Lafuente Millán, Enrique. 2010. 'Extending this claim, we propose...'. The writer's presence in research articles from different disciplines. Ibérica 20:35-56.

May, Sir Robert. 2002. 'I did' or 'It was done'?". TSNews 15: 1-2 [reprinted in Osmosis (2003: 42, 3)].

Minton, Timothy D. 2015. In defense of the passive voice in medical writing. The Keio Journal of Medicine 64 (1): 1-10.

O'Donnell, Michael, Michele Zappavigna, and Casey Whitelaw. 2008. A survey of process type classification over difficult cases. In New developments in the study of ideational meaning: From language to multimodality, ed. Carys Jones and Eija Ventola, 47-64. London: Continuum.

Seoane, Elena. 2006. Changing styles: On the recent evolution of scientific British and American English. In Syntax, style and grammatical norms: English from 1500-2000, ed. Christiane Dalton-Puffer, Dieter Kastorsky, Nikolaus Ritt, and Herbert Schendl, 191-209. Bern: Peter Lang.

Seoane, Elena, and Lucia Loureiro-Porto. 2005. On the colloquialization of scientific British and American English. ESP Across Cultures 2: 106-116

Seoane, Elena, and Christopher Williams. 2006. Changing the rules: A comparison of recent trends in English in academic scientific discourse and prescriptive legal discourse. In Diachronic perspectives on domain-specific English, ed. Marina Dossena and Irma Taavitainen, 255-276. Bern: Peter Lang.

Tarone, Elaine, Sharon Dwyer, Susan Gillette \& Vincent Icke. 1981. On the use of the passive in two astrophysics journal papers. ESP Journal. 1(2): 121-139 [reprinted in Swales, John (ed.) 1985:191-205.

Tarone, Elaine, Sharon Dwyer, Susan Gillette, and Vincent Icke. 1998. On the use of passive and active voice in astrophysics journal papers: With extensions to other language and other fields. English for Specific Purposes 17 (1): 113-132.

Submit your manuscript to a SpringerOpen ${ }^{\circ}$ journal and benefit from:

- Convenient online submission

- Rigorous peer review

Open access: articles freely available online

High visibility within the field

Retaining the copyright to your article

Submit your next manuscript at $>$ springeropen.com 